\title{
LOCAL RECURRENCE AFTER AMPUTATION FOR OSTEOSARCOMA
}

\author{
M. CAMPANACCI, M. LAUS \\ From the First Orthopaedic Clinic of the University of Bologna, \\ Istituto Ortopedico Rizzoli, Bologna
}

Two hundred and forty-eight high-grade central osteosarcomata were treated by amputation or disarticulation; in 5.2 per cent the tumour recurred at the amputation site. The following causes may be responsible for local recurrence: the level of the amputation is too close to the tumour; there is an unrecognised intramedullary extension of the tumour; during a previous block resection tumour cells may have been seeded in the soft tissues; the primary tumour was too extensive even for radical surgery; "skip" metastases may have been present; iatrogenic tumour implantation may have occurred while a biopsy was being performed during the course of an amputation. Treatment of the primary osteosarcoma should take all these possibilities into account.

In our experience adjuvant chemotherapy has not significantly changed the frequency of local recurrences which should be treated by radical operation or, if this is not possible, by irradiation; chemotherapy may be used as an adjuvant. The prognosis of local recurrences is bad.

Central high-grade osteosarcoma does not respond well to radiotherapy, nor is en bloc resection usually adequate; consequently the standard treatment is amputation. This study concerns local recurrence after amputation for osteosarcoma.

\section{MATERIAL AND METHODS}

Two hundred and forty-eight patients with central high-grade osteosarcoma treated in our Institute by

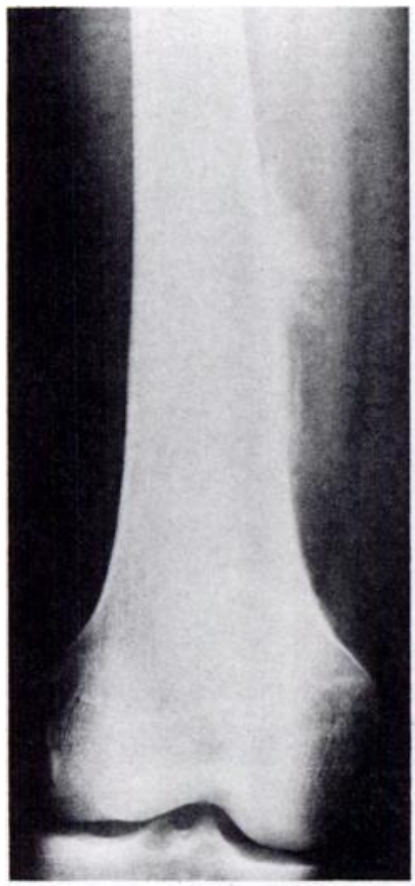

Fig. 1

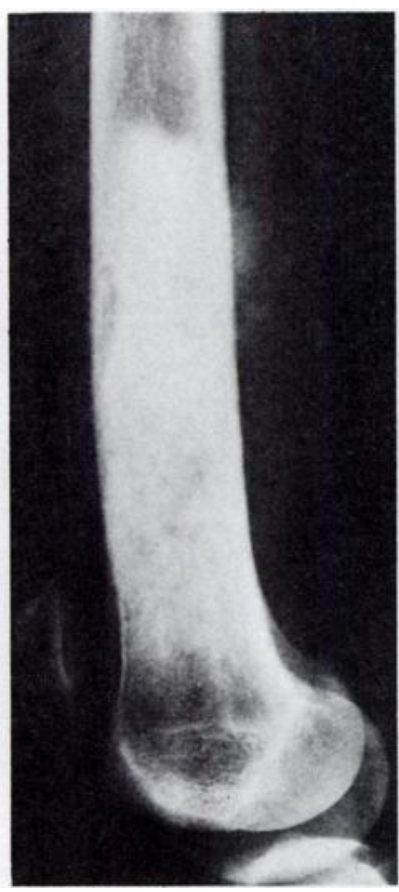

Fig. 2 amputation or disarticulation have been studied (Table I). All have been followed up until distant metastases appeared, or for at least three years after amputation. Of these 248 patients, 13 presented with local recurrence on the amputation or disarticulation stump (Table II). We have not included those local recurrences which appeared only in the terminal stages when there was already multiple metastatic diffusion in the skeleton (Figs 1 to 3 ).

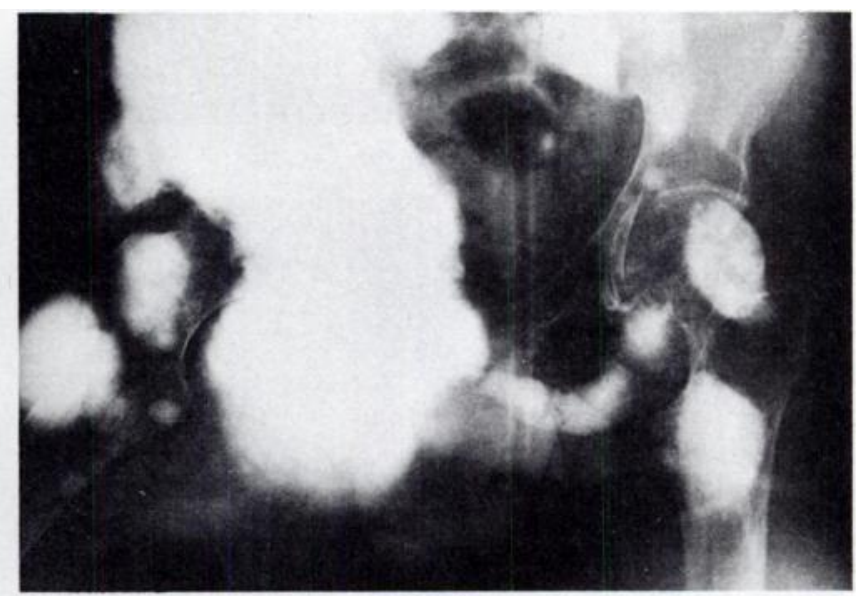

Fig. 3

Male aged 22. Figures 1 and 2-Sclerosing osteosarcoma of the distal right femur treated by high thigh amputation. Figure 3 - Two years after amputation multiple bony metastases appeared in the skull. humerus, vertebrae, pelvis, upper left femur, and also in the bony stump of the right femur. This stump involvement should not be regarded as a local recurrence; it is a metastasis. Two years and eight months after amputation, the patient died with pulmonary metastases.

M. Campanacci, MD. Director First Orthopaedic Clinic of the University of Bologna,

M. Laus, MD, Resident $\}$ Istituto Ortopedico Rizzoli, Via Codivilla 9, Bologna, Italy.

Requests for reprints should be sent to Professor Campanacci. 


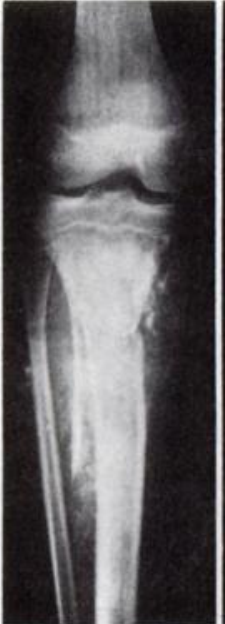

Fig. 4

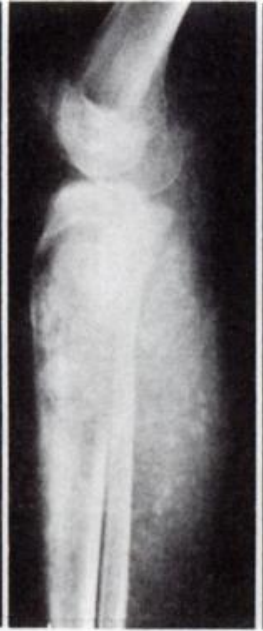

Fig. 5

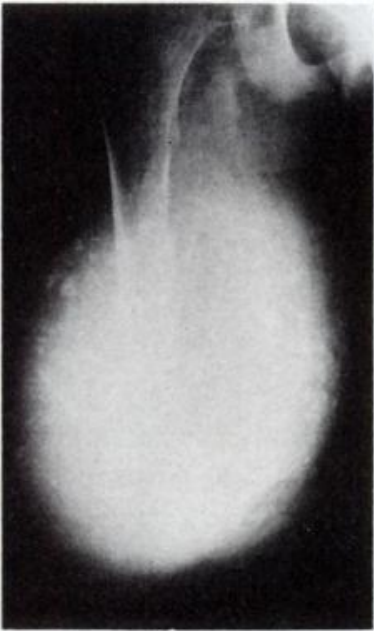

Fig. 6

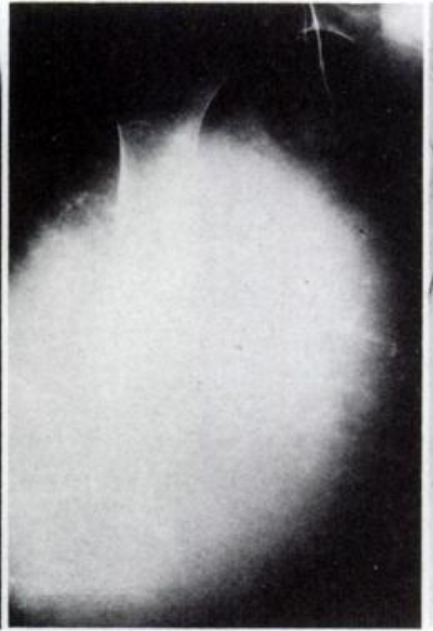

Fig. 7

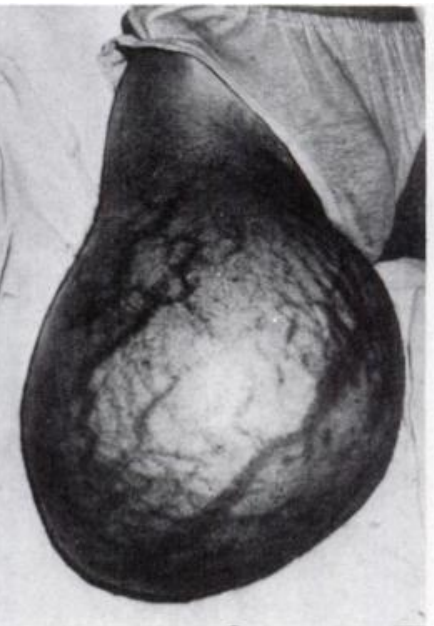

Fig. 8

Case 4-Male aged 17. Figures 4 and 5-Osteosarcoma of the proximal metaphysis of the right tibia, treated by above-knee amputation with intra-operative biopsy with frozen sections. Figure 6-Sixteen months later a local recurrence in the stump appeared at the same time as pulmonary metastases. The patient was given chemotherapy. Figure 7-Four months after diagnosis of the local recurrence the neoplastic mass has reached a tremendous size. Figure 8 - Twenty months after amputation the stump is bulky, painful and swollen, with a subcutaneous venous network, redness and warmth of the skin. He died 21 months after the amputation.

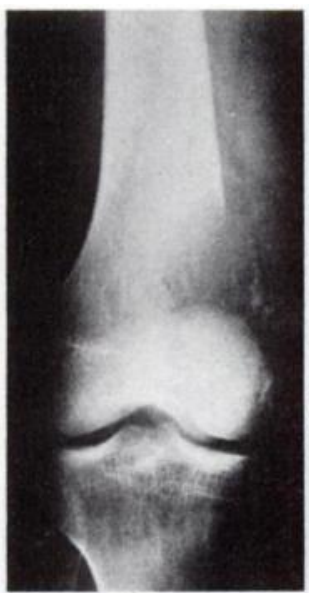

Fig. 9

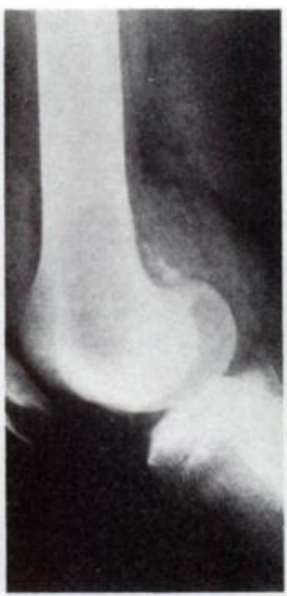

Fig. 10

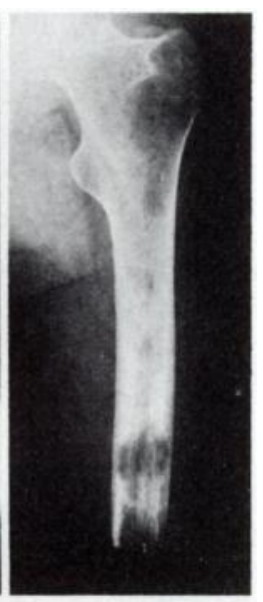

Fig. 11

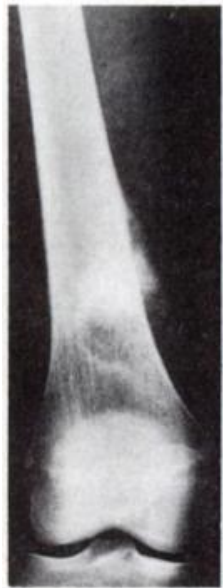

Fig. 12

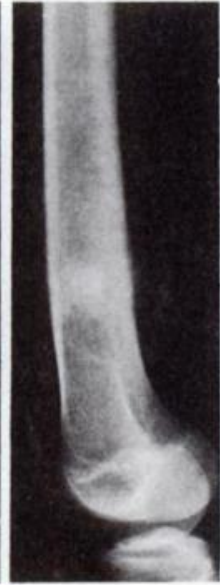

Fig. 13

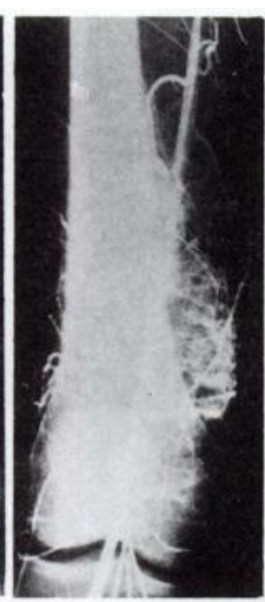

Fig. 14

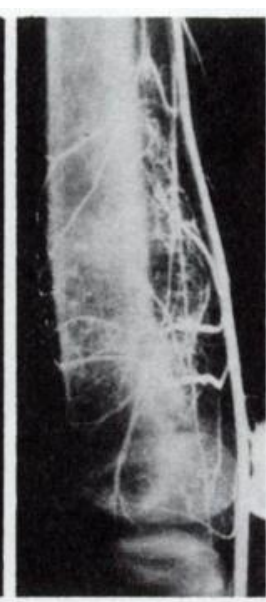

Fig. 15

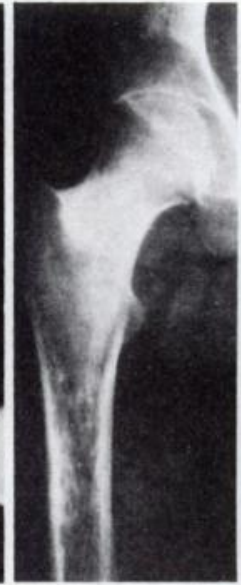

Fig. 16

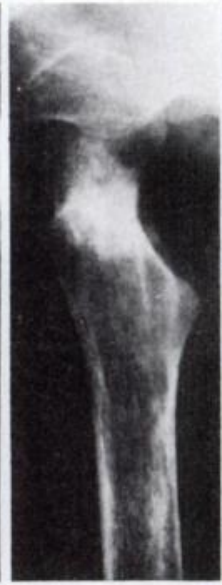

Fig. 17

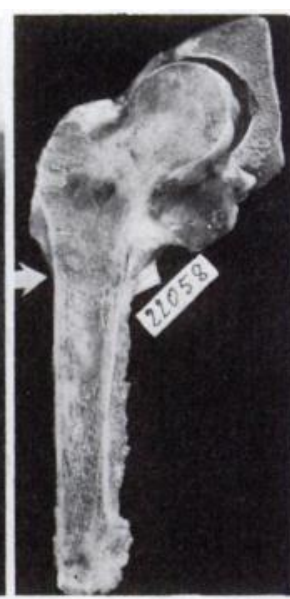

Fig. 18

Case 10-Female aged 14. Figures 12 and 13-Osteosarcoma of the distal right femur. Figures 14 and 15 -The arteriogram shows extension of the tumour into the soft tissues with impingement on the popliteal artery. High thigh amputation was performed with intra-operative biopsy; the bone marrow at the transection level was examined histologically and no tumour found. Figures 16 and $17-$ Six months later a local recurrence appeared in the bony stump as shown by a sclerotic area in the femoral neck. Hindquarter amputation was performed but, eight months after the second amputation, a new recurrence appeared. Figure 18-Macroscopic appearance of the bony stump: the proximal part of the femur, above the arrow, is completely infiltrated by the predominantly sclerotic tumour. The darkest area is the site of the biopsy which preceded the second amputation. The portion of the bony stump below the arrow was checked by multiple sections and was not involved by the tumour. The homogeneous material in the subtrochanteric area is normal bone marrow. 


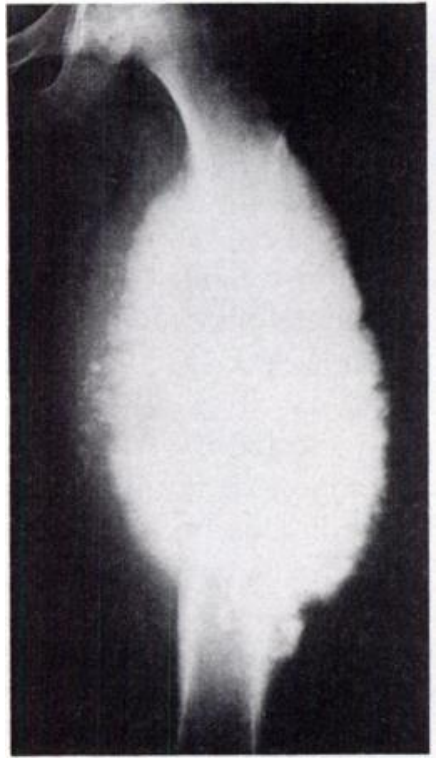

Fig. 19

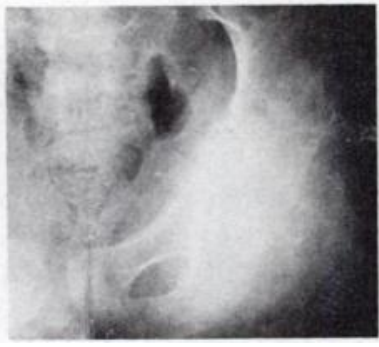

Fig. 20

Case 7-Male aged 16. Figure 19-Sclerosing osteosarcoma treated by disarticulation of the hip. Figure 20-Five months later a local recurrence appeared in the soft tissues of the stump and in the ilium, with intrapelvic extension. He was treated by local excision and radiotherapy, but died with pulmonary metastases 13 months after the disarticulation. At autopsy additional metastases were found in the pancreas.

Defined thus, the local recurrence rate was 5.2 per cent. The interval between amputation and local recurrence ranged from two months to seven years with an average of 12 months. Clinically the local recurrence presented with pain, swelling, or both; in the absence of adequate treatment the swelling may reach a tremendous size (Case 4: Figs 4 to 8). Sometimes phenomena
Table I. Amputations and disarticulations for osteosarcoma

\begin{tabular}{|c|c|}
\hline High thigh amputations for osteosarcoma of distal femur & 120 \\
\hline Above-knee amputations for osteosarcoma of proximal tibia & 64 \\
\hline Disarticulations of the hip & 35 \\
\hline Forequarter amputations & 10 \\
\hline Hindquarter amputations & 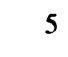 \\
\hline Other types of amputation & 14 \\
\hline Total & 248 \\
\hline
\end{tabular}

such as a phantom limb or intolerance to the prosthesis preceded the clinical and radiological appearance of a local recurrence by a few months. In two cases a pathological fracture of the stump was the presenting feature.

\section{RADIOGRAPHIC APPEARANCE}

The local recurrence has radiographic characteristics similar to those of the primary tumour; it may be mainly osteolytic (Case 2: Figs 9 to 11), or osteosclerotic (Case 10: Figs 12 to 18) or both (Figs 4 to 7). In eight instances the recurrence involved both the bone and the soft tissues (Fig. 6; Case 7: Figs 19 and 20), in two it was limited to bone (Fig. 11; Figs 16 and 17), while in three it involved only the soft tissues, and in such cases the radiograph may be normal.

Table II. Local recurrences after amputation for osteosarcoma

\begin{tabular}{|c|c|c|c|c|c|c|c|c|}
\hline Case & Sex & $\underset{\text { (years) }}{\text { Age }}$ & Site & Amputation & $\begin{array}{c}\text { Recurrence } \\
\text { (months) }\end{array}$ & $\begin{array}{l}\text { Treatment of the } \\
\text { recurrence }\end{array}$ & $\begin{array}{c}\text { Follow-up } \\
\text { (time since recurrence) }\end{array}$ & $\begin{array}{l}\text { Pulmonary } \\
\text { metastases }\end{array}$ \\
\hline 1 & $\mathbf{M}$ & 28 & Ilium & Hindquarter & 10 & Radiation & Dead after 11 months & Yes \\
\hline * 2 & $\mathbf{M}$ & 18 & Distal femur & $\begin{array}{l}10 \text { centimetres } \\
\text { above tumour }\end{array}$ & 10 & Radiation & Dead after 18 months & Yes \\
\hline$* 3$ & $\mathbf{M}$ & 13 & Proximal tibia & Above knee & 5 & Hindquarter & Dead after 5 months & Yes \\
\hline$* 4$ & $\mathbf{M}$ & 17 & Proximal tibia & Above knee & 16 & None & Dead after 5 months & Yes \\
\hline 5 & $\mathbf{M}$ & 51 & Proximal humerus & Forequarter & 2 & Radiation & Dead after 3 months & Yes \\
\hline 6 & $\mathbf{F}$ & 26 & Distal femur & $\begin{array}{l}6 \text { centimetres } \\
\text { above tumour }\end{array}$ & 3 & $\begin{array}{l}\text { Disarticulation of } \\
\text { hip }\end{array}$ & Dead after 5 months & Yes \\
\hline 7 & $\mathbf{M}$ & 16 & Proximal femur & $\begin{array}{l}\text { Disarticulation of } \\
\text { hip }\end{array}$ & 5 & $\begin{array}{l}\text { Excision and } \\
\text { radiation }\end{array}$ & Dead after 8 months & $\begin{array}{c}\text { Yes } \\
\text { (and pancreas) }\end{array}$ \\
\hline 8 & $\mathbf{M}$ & 44 & Proximal humerus & $\begin{array}{l}\text { Disarticulation of } \\
\text { shoulder }\end{array}$ & 3 & Excision (twice) & Dead after 23 months & Yes \\
\hline 9 & $\mathbf{M}$ & 25 & Proximal femur & $\begin{array}{l}\text { Disarticulation of } \\
\text { hip }\end{array}$ & 6 & Radiation & Dead after 6 months & Yes \\
\hline${ }^{*} 10$ & $\mathrm{~F}$ & 14 & Distal femur & $\begin{array}{l}10 \text { centimetres } \\
\text { above tumour }\end{array}$ & 6 & $\begin{array}{l}\text { Hindquarter } \\
\text { amputation }\end{array}$ & $\begin{array}{l}\text { New recurrence in the } \\
\text { stump after } 8 \text { months }\end{array}$ & - \\
\hline 11 & $\mathbf{M}$ & 47 & Proximal femur & $\begin{array}{l}\text { Disarticulation of } \\
\text { hip }\end{array}$ & 4 & Radiation & Dead after 1 month & Yes \\
\hline 12 & $\mathrm{~F}$ & 15 & Midshaft femur & $\begin{array}{l}3 \text { centimetres } \\
\text { above tumour }\end{array}$ & 3 & Radiation & Dead after 6 months & Yes \\
\hline${ }^{*} 13$ & $\mathbf{M}$ & 15 & Distal femur & $\begin{array}{l}10 \text { centimetres } \\
\text { above tumour }\end{array}$ & 84 & Treatment refused & - & - \\
\hline
\end{tabular}

${ }^{*}$ Intra-operative biopsy by frozen sections. Note: Only in Case 10 was there histological checking of the bone marrow at the amputation site. 


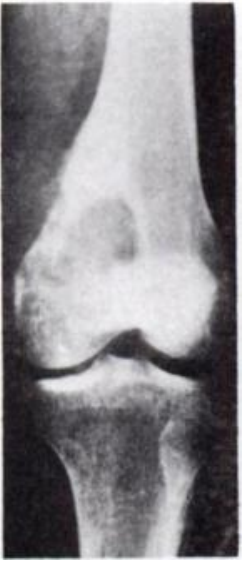

Fig. 21

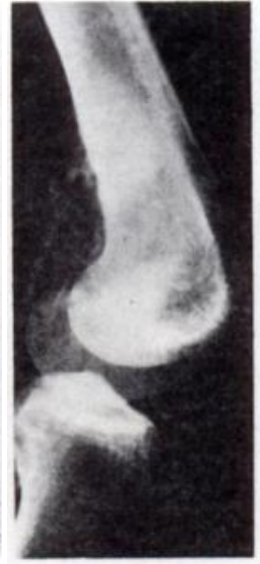

Fig. 22

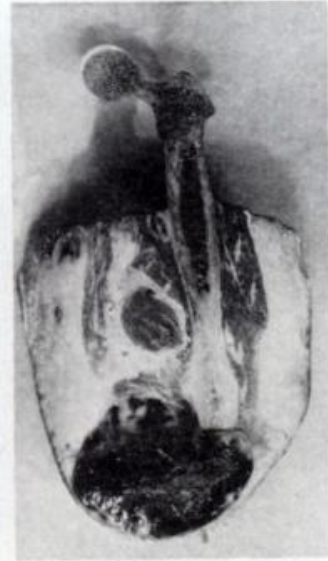

Fig. 23
Case 6-Female aged 26. Figures 21 and 22-Predominantly haemorrhagic osteosarcoma of the distal left femur treated by amputation through the thigh. A previous en bloc resection had been followed by local recurrence. Three months after the amputation a local recurrence appeared in the soft tissues of the stump and disarticulation of the hip was performed. Figure 23-Macroscopic appearance of the recurrence: a haemorrhagic neoplastic mass involves the soft tissues at the apex of the stump. Five months after the second amputation the patient died with pulmonary metastases.

\section{PATHOLOGICAL FINDINGS}

The macroscopic appearances correspond to the radiographic picture. Thus, the amputation stump may be diffusely infiltrated by the recurrent tumour with wide involvement of the bone and the soft tissues (Figs 6 and 7 ), or the recurrence may be limited to the soft tissues (Case 6: Figs 21 to 23), or to bone (Fig. 18). When only the bone is affected, either the apex of the bony stump is involved by the tumour growing proximally along the medullary canal (Fig. 11), or the recurrence involves the bone at some distance from the apex, which itself is unaffected (Figs 16 to 18 ). This anatomical distinction depends upon the cause of the local recurrence. The macroscopic appearance of the recurrence resembles that of the primary, being mostly osteoblastic (Fig. 18), chondroblastic, fibroblastic, or haemorrhagic (Fig. 23).

Histologically, in all our patients, the primary tumour was of high-grade malignancy (Grade 3 or 4 according to Broders 1926). For this reason it was not possible to demonstrate a progression of malignancy in the local recurrence.

\section{DIAGNOSIS}

Diagnosis of local recurrence is easy in the presence of pain, swelling, or obvious radiographic involvement of the stump. In two patients, however, diagnosis was more difficult. In one the recurrence was limited to the soft tissues, the radiographs were negative, and the recurrence was at first considered to be a haematoma (Case 6 ); in the other the lesion was a small one confined to the bony stump in a patient who complained of mild discomfort suggesting intolerance to the prosthesis (Case 10). A firm diagnosis can, of course, be established by biopsy.

\section{PATHOGENESIS}

Various factors may account for local recurrence of an osteosarcoma despite ablative surgery. The amputation may not be sufficiently radical: neither amputation close to the tumour nor en bloc resection is likely to result in complete removal. A preceding en bloc resection may have disseminated the tumour into the soft tissues, so that the level of subsequent amputation needed to be unusually high. On rare occasions the osteosarcoma extends along the medullary canal (Figs 24 to 26), sometimes beyond the limits indicated by the radiographs (Dahlin 1978), so that the usual level of bony section is inadequate. Sometimes, especially with tumours of the scapula, ilium, proximal humerus and proximal femur with wide invasion of the soft tissues, complete removal of the primary tumour is impossible, even with such mutilating procedures as forequarter or hindquarter amputation. When, immediately before amputation, a biopsy is taken for frozen section, there is a definite risk of implanting tumour cells. Finally, local recurrence may be due to pre-existing "skip" metastases; that is neoplastic foci contemporary with, but separate from, the primary lesion. These "skip" metastases may be either in the medulla of the same bone as the primary, or in the bone proximal to the adjacent joint (Enneking and Kagan 1975); they probably arise from neoplastic embolisation of the sinusoids in the marrow cavity and of the valveless venous networks connecting the two metaphyses adjacent to the joint.

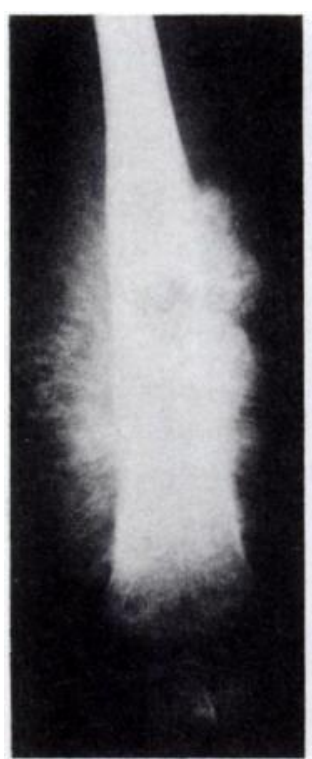

Fig. 24

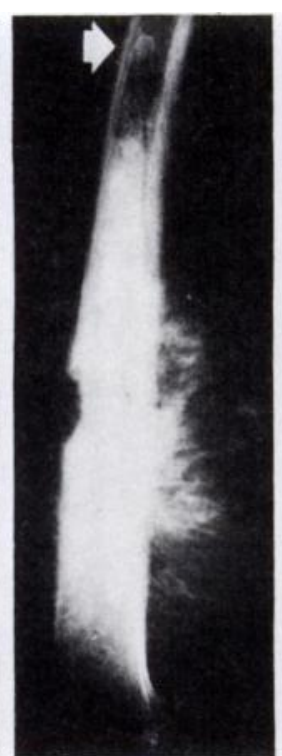

Fig. 25

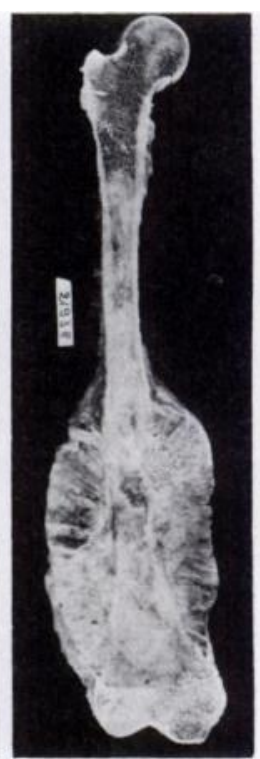

Fig. 26
Male aged 16. Figures 24 and 25-Sclerosing osteosarcoma with typical "sunburst" appearance of the distal femur. The biopsy site is evident. In the lateral radiograph an intramedullary extension of the tumour is revealed by a slightly dense round area (arrow). This patient was treated by disarticulation of the hip and has no evidence of disease six months later. Figure 26-The macroscopic specimen shows an intramedullary extension of the tumour up to the subtrochanteric area. 


\section{ANALYSIS}

The 13 cases of our series (Table II) differ in regard to site, type of amputation, adjuvant chemotherapy, and treatment of the local recurrence. They do, however, represent a spectrum of the different situations which need to be considered in planning amputations for osteosarcoma. It is not possible to be certain of the pathogenesis of the local recurrences in our cases, but we can suggest which of the factors already described was responsible in each.

In Case 1 in which the ilium was involved, and in Case 5 in which the humerus was affected with massive invasion of the soft tissues in the axilla, the tumour was not amenable to amputation. In Cases 6, 7, 8, 9, 11 and 12 the amputation or disarticulation was too close to the primary tumour (Figs 19 and 20); moreover a preceding en bloc resection in Cases 6, 8 and 9 may have disseminated the tumour in the soft tissues (Figs 21 to 23). Case 10 (Figs 12 to 18) is a typical example of "skip" metastasis: the local recurrence is totally intra-osseous, the apex of the bony stump is not involved, and the bone marrow at the level of the amputation had been histologically checked during the operation.

Case 2, in which the distal femur was affected (Figs 9 to 11 ), shows radiographically a local recurrence which involves both the apex of the bony stump and the proximal medullary canal; this local recurrence could be due to an intramedullary extension of the primary tumour which was not appreciated at the time of operation.

In Cases 3 and 4 the amputation had been carried out above the joint proximal to the tumour. It is commonly believed that local recurrence is then unlikely (Campanacci and Cervellati 1975; Dahlin 1978; Sim, Ivins and Pritchard 1978), though Enneking and Kagan (1975) demonstrated that metastases can "skip" over a joint. This might have been the cause in our two cases, but the possibility of iatrogenic implantation during biopsy cannot be excluded.

In Case 13, affecting the distal femur, the recurrence appeared 84 months after high thigh amputation. The radiographic appearance of the recurrence suggests a central origin in the bony stump; we believe that this case represents a "skip" metastasis but the long interval between the ablative surgery and the recurrence is puzzling.

\section{PROGNOSIS AND TREATMENT}

Local recurrence after amputation for osteosarcoma carries a very bad prognosis, no matter what treatment is subsequently employed. Eleven of our 13 patients died with pulmonary metastases 3 to 33 months after the local recurrence; the average survival time was eight months. One patient (Case 10) presented with a new recurrence in the stump eight months after hindquarter amputation for a recurrence in the thigh stump. Another patient (Case 13) refused all treatment; at the time his recurrence was diagnosed he was free of distant metastases. Both are recent patients and are still alive.

A painful stump should be carefully investigated and, if a diagnosis of local recurrence is made, then local treatment must begin immediately, since chemotherapy alone is inadequate (Case 4). In the absence of distant metastases, the best treatment is re-amputation at a more proximal level. When this is not feasible radiotherapy, which may alleviate the local symptoms, is employed. Chemotherapy is used as an adjuvant.

\section{DISCUSSION}

The incidence of local recurrences after amputation for osteosarcoma has been evaluated by several authors. Some report a recurrence rate as low as three or four per cent (Dahlin and Coventry 1967; Hill 1973; Campanacci and Cervellati 1975; Price et al. 1975; Sim et al. 1978). Others report figures as high as 16 per cent (McKenna et al. 1966; Moore, Gerner and Brugarolas 1973; Sweetnam 1973). These latter, however, included terminal cases, in which metastases in the bony stump might have been confused with local recurrence, as in Figure 3 (Lewis and Lotz 1974; Romsdahl and Ayala 1977).

Those authors who report the higher figures advise disarticulation of the hip for osteosarcoma of the distal femur. We disagree; in our series the recurrence rate after amputation through the thigh for osteosarcoma of the distal femur is only 3.3 per cent. There is no evidence from the literature to suggest that the survival rate is any higher after disarticulation than after amputation through the upper thigh (Lewis and Lotz 1974). Moreover, disarticulation of the hip causes more surgical shock, is more difficult to fit with a prosthesis and, by lowering the immunological defences, may even increase the chance of metastases (Goidanich et al. 1966; Campanacci and Cervellati 1975).

There is also a difference of opinion regarding the influence of chemotherapy on the frequency of local recurrence. Sweetnam $(1973,1975)$ maintained that, before adjuvant chemotherapy was used, osteosarcomata of the distal femur were best treated by disarticulation of the hip; but that with chemotherapy, which may destroy microfoci of tumour cells in the stump, amputation through the thigh is reasonable. Sim et al. (1978) suggest that local recurrence may become a more common problem if chemotherapy leads to longer survival. However, we have found no significant difference in the local recurrence rate since the introduction of adjuvant chemotherapy: of 76 patients with osteosarcoma treated by amputation and adjuvant chemotherapy between 1972 and 1977 and followed up for one to five years, three (four per cent) developed local recurrences (Cases 3, 4 and 10).

Study of our cases suggests the following observa- 


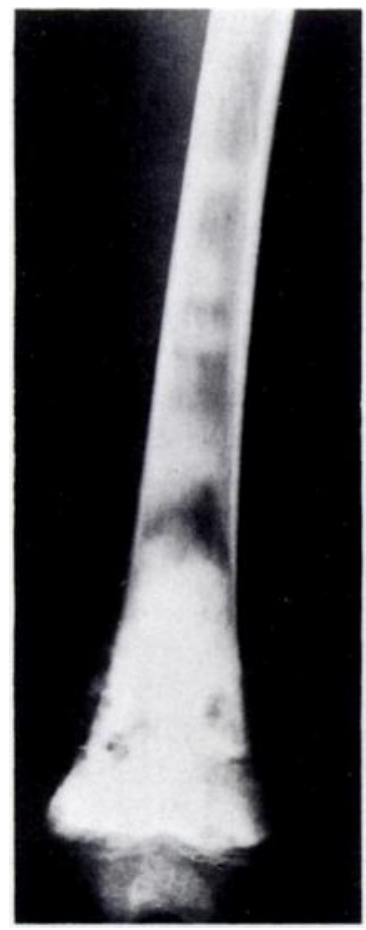

Fig. 27

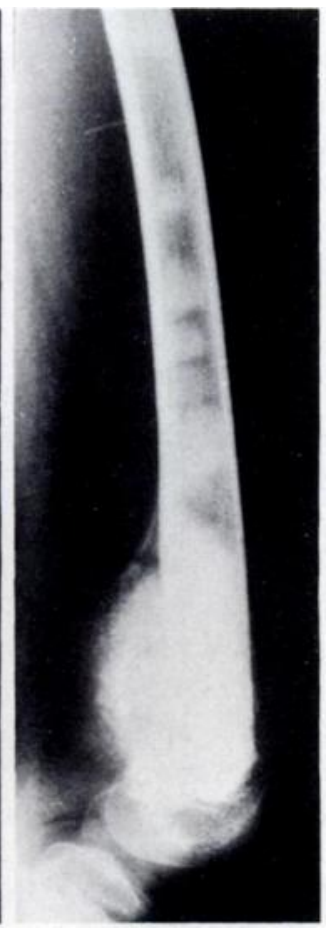

Fig. 28
Female aged nine. Sclerosing osteosarcoma of the distal metaphysis of the femur: along the medullary canal several round areas of osteosclerosis are evident and reveal the intramedullary extension of the tumour. The parents refused amputation. Lacking a pathological specimen we do not know if this was an example of continuous intramedullary extension of the tumour, or of several "skip" metastases. tions regarding amputation for primary osteosarcoma. In a suspected case radiographs should always include the entire length of the affected bone, in order to search for possible intramedullary extension of the tumour (Figs 24 to 26) or for "skip" metastases (Figs 27 and 28). When the proximal tibia is affected then, by the same token, radiographs of the ipsilateral distal femur also should be taken. These studies can be augmented by tomography and bone scanning.

Sometimes angiography is useful in evaluating extension of the tumour into the soft tissues. More exhaustive information regarding extension along the medullary canal or into the soft tissues may be obtained by computerised tomography.

At the primary operation most surgeons take a biopsy specimen and await the result of frozen sections before proceeding; great care must be taken to avoid implanting neoplastic cells into the stump; the instruments used for the biopsy, the sheets, the gowns and gloves, should all be changed before performing the amputation. During amputation, when the bone is cut across, its marrow should be examined histologically by frozen section. As a general rule amputation should be performed either through the bone proximal to the joint above the tumour, or if through the bone which contains the tumour then at least 10 centimetres proximal to the upper limit of the tumour as shown on radiographs (Campanacci and Cervellati 1975).

Disarticulation of the hip is indicated for tumours of
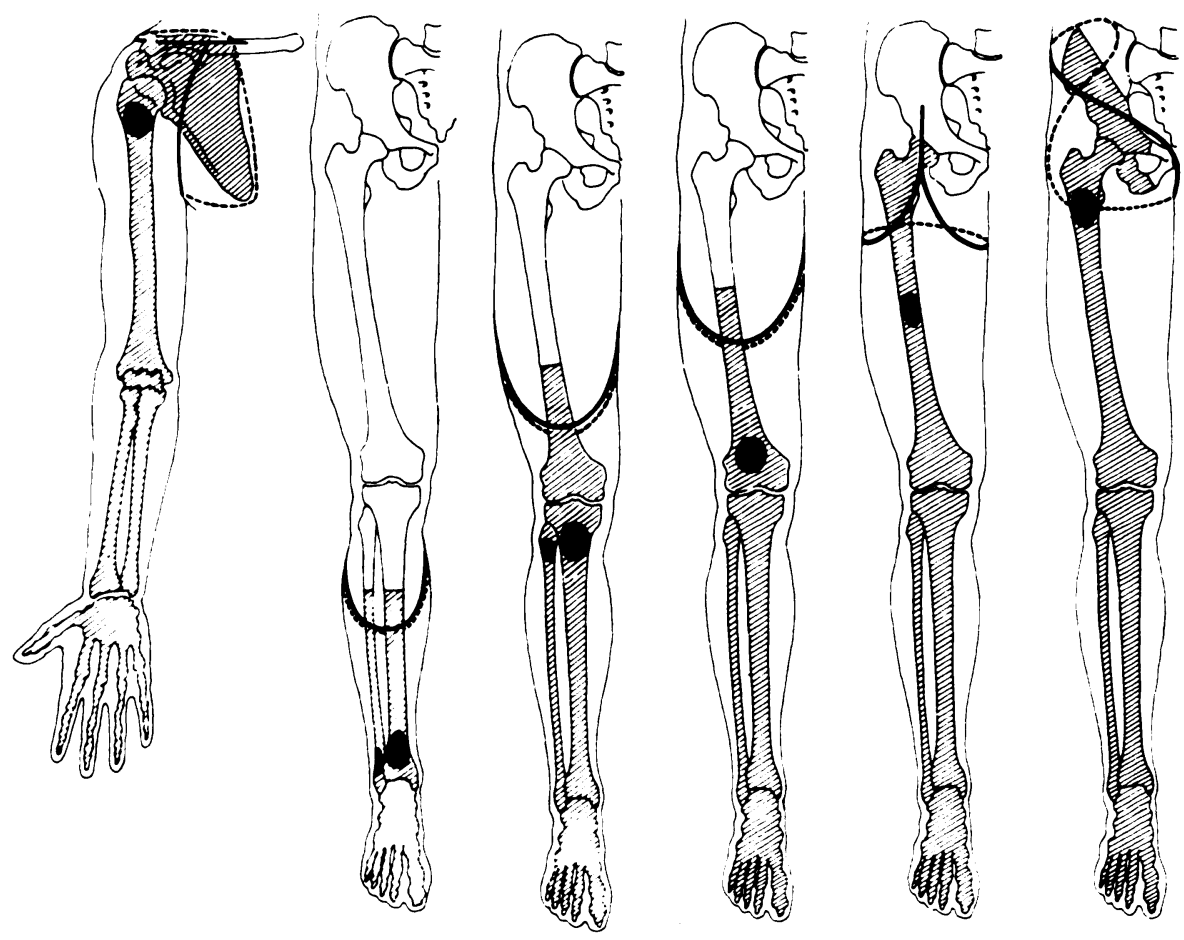

Fig. 29

Amputation levels for osteosarcoma. From left to right: forequarter amputation, below-knee amputation, above-knee amputation, high thigh amputation, disarticulation of the hip and hindquarter amputation. 
the middle third of the femur; but with tumours of the proximal third disarticulation does not prevent local recurrence and hindquarter amputation is needed.

Figure 29 shows the amputation levels required in the treatment of osteosarcoma. By adopting these levels and taking the precautions already described, the local recurrence rate should come down to little more than two per cent.

\section{REFERENCES}

Broders AC. Carcinoma-grading and practical application. Arch Pathol Lab Med 1926:2:376-81.

Campanacci M, Cervellati C. Osteosarcoma. A review of 345 cases. Ital J Orthop Traumatol 1975;1:5-22.

Dahlin DC. Bone tumors. 3rd ed. Springfield, Illinois: Charles C Thomas, 1978:226-60.

Dahlin DC, Coventry MB. Osteogenic sarcoma: a study of 600 cases. J Bone Joint Surg [Am] 1967;49-A:101-10.

Enneking WF, Kagan A. "Skip" metastases in osteosarcoma. Cancer 1975;36:2192-2205.

Goidanich IF, Battaglia L, Lenzi L, Silva E. Osteogenic sarcoma. Analysis of factors influencing prognosis in 100 cases. Clin Orthop $1966 ; 48: 209-22$.

Hill P. Local recurrence in primary osteosarcoma of the femur. Br J Surg 1973;60:40-1.

Lewis RJ, Lotz MJ. Medullary extension of osteosarcoma: implications for rational therapy. Cancer 1974;33:371-5.

McKenna RJ, Schwinn CP, Soong KY, Higinbotham NL. Sarcomata of the osteogenic series (osteosarcoma, fibrosarcoma, chondrosarcoma, parosteal osteogenic sarcoma, and sarcomata arising in abnormal bone): an analysis of 552 cases.J Bone Joint Surg [Am] 1966;48-A:1-26.

Moore GE, Gerner RE, Brugarolas A. Osteogenic sarcoma. Surg Gynecol Obstet 1973;136:359-66.

Price CHG, Zhuber K, Salzer-Kuntschik M et al. Osteosarcoma in children. A study of 125 cases. J Bone Joint Surg [Br] 1975;57-B:341-5.

Romsdahl MM, Ayala AG. Surgical management of osteosarcoma. In: Anderson Hospital and Tumor Institute. Management of primary bone and soft tissue tumors. Chicago and London: Year Book Medical Publications, 1977.

Sim FH, Ivins JC, Pritchard DJ. Surgical treatment of osteogenic sarcoma at the Mayo Clinic. Cancer Treat Rep 1978;62:205-11.

Sweetnam R. Amputation in osteosarcoma. J Bone Joint Surg [Br] 1973;55-B:189-92.

Sweetnam R. Amputation in osteosarcoma. J Bone Joint Surg [Br] 1975;57-B:268-9. 